\title{
Experimental Investigation in Micro Ball-End Milling of
}

\section{Hardened Steel}

\author{
Bérenger Escolle*, Michael Fontaine, Alexandre Gilbin, Sébastien Thibaud and Philippe Picart \\ FEMTO-ST Institute, UMR 6174, Department of Applied Mechanics, CNRS/UFC/ENSMM/UTBM/UBFC, 24 Chemin de l'Epitaphe, \\ 25000 Besançon, France
}

\begin{abstract}
The study focuses on micro-milling of a hardened tool steel with micro ball-end mills. The purpose is to observe the capability of a set of these mills to machine hard steels used for tooling applications. Different cutting configurations are here tested in order to evaluate their performance and finally enhance their design in this context. Experimental data, in terms of cutting forces, surfaces integrity and machining errors, is obtained from machining tests on a 40NiCrMo 16 hardened steel with $0.5 \mathrm{~mm}$ diameter coated tungsten carbide micro-tools. The results allow highlighting some cutting, wear and dynamical phenomena related to the process. They are mainly associated to the types of mill and cutting conditions, as feed or tool/surface inclination. In this paper, the tool geometry and its dynamical behavior are mainly discussed.
\end{abstract}

Key words: Micro-milling, ball-end milling, tungsten carbide, PVD coating, hardened steel, tool geometry, tool deflection.

\section{Glossary}

PVD Physical vapor deposition

$R_{x y z} \quad$ Resultant cutting force

$N \quad$ Spindle speed (rpm)

$d_{n} \quad$ Normal depth of cut $(\mu \mathrm{m})$

$\delta_{f} \quad$ Inclination from feed direction

$\delta_{n} \quad$ Inclination from a direction normal to the feed

$f_{t} \quad$ Feed per tooth $(\mu \mathrm{m} /$ tooth $)$

$S q \quad$ Root mean square height $(\mu \mathrm{m})$

SEM Scanning electron microscope

\section{Introduction}

The increasing demand for micro-components needs to control and develop the dedicated manufacturing processes. Among existing processes, micro-milling is one of the most versatile. From a down-scaling of conventional machining, micro-milling can be defined by the use of tools less than one millimeter in diameter [1]. This leads to be applicable in a wide range of materials and to allow shaping complex 3D geometry and relatively high shape ratio parts [2]. However, miniaturizing the process increases the impact of several phenomena which are often overlooked or

"Corresponding author: Bérenger Escolle, Ph.D., research field: micro manufacturing. simplified when considering conventional machining. In micromachining, material removal rate is considerably low compared to that in conventional machining [3]. The nano/micro-scale cutting is a singular material removal process because the undeformed chip thickness ranges from a few nanometers to a few microns. Unlike in conventional macro-scale machining, undeformed chip thickness can be typically comparable in size to the cutting edge radius. This size effect is well identified in micro-milling and strongly impacts the performance of the tool [4] and the surface generation [5]. The dimensional characteristics of these tools accentuate deflection [6] and dynamic instability [7]. When machining with micro-tools, it is often observed tool vibrations and cutting instabilities [8, 9], usually gathered in chatter instability issues. The local micro-cutter geometries are inheriting a "downscaling" of conventional geometries. Li P. et al [10] demonstrated the importance to develop specific local geometries (helix angle, orthogonal rake angle) and neck geometries for micromachining. The results obtained with different experimental conditions show a 
clear increase in performance with an optimized micro-mill against a commercial mill.

This paper presents a study dealing with micro ball-end mills optimization for precision machining of hardened tool steels. The typical targeted application is the production of plastic injection molds. $0.5 \mathrm{~mm}$ diameter micro ball-end mills are considered here. The efficiency of micro-milling cutters selected from different manufacturers has been tested for various machining conditions. Some parameters and perturbations have been identified. Phenomena related to the micro-milling process have been highlighted from the obtained experimental data based on in-time measurements and post-observations. The influence of tool properties and cutting conditions here is presented in terms of generated cutting forces, surfaces quality and tools wear. In the first part, experimental setup and global approach of the study are presented. In the second part, the results are given and the influence of the feed rate and tilt angles is discussed. Finally, the relationship between tool wear, local tool geometry and feed rate is investigated to define the more adapted tool geometry and cutting conditions for a set of slotting and surfacing milling configurations.

\section{Experimental Setup}

\subsection{Work Piece Material}

The machined material is a $40 \mathrm{NiCrMo} 16$ steel presenting a micro-hardness equal to $54 \mathrm{HRC}( \pm 1)$. This material is commonly used to manufacture plastic injection molds. A thermal treatment provides a fine and homogeneous submicronic martensitic structure (Fig. 1).

The chemical composition is presented in table 1 . In this study, size effect due to grain size described by Bissaco G. et al. [11] does not introduce any dispersion in cutting forces measurement or in effective tools life.
The main influent parameter to consider here is the tool edge radius/chip thickness ratio.

\subsection{Tools}

The tested tools are $0.5 \mathrm{~mm}$ diameter micro-grain tungsten carbide ball-end mills. These micro-mills have 2 flutes and are PVD coated. Fig. 2 shows the global geometry of the four types of cutters used in this study.

Table 2 summarizes the main properties of these four micro-mills. Types 1, 3 and 4 are close to conventional tools with respect to their local geometry (cutting angle, clearance, flute and helix). This choice aims to be representative of mills available on international market. It allows also comparing two reference models from our industrial partner with those of two main competitors. The type 2 has a cutting edge preparation, a null rake angle at the end, and that leads to a stronger edge. It is important to note that each mill possesses a different global geometry because this may impact their dynamic behavior (Fig. 2). The tool breakage force values presented in Table 2 are obtained from the average of two instrumented 3 -axes milling tests.

\subsection{Machine-Tool and Measuring Devices}

The study was carried out in an industrial mold making context. For this reason, a range of spindle speed from 0 to $42,000 \mathrm{rpm}$ was used and the micro-milling tests were performed on an Agie-Charmilles

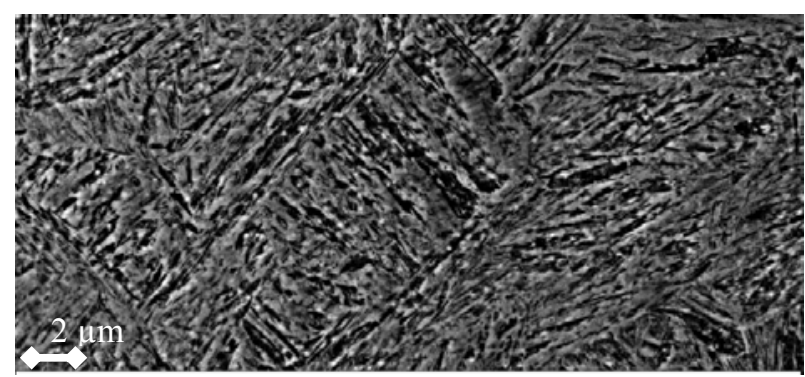

Fig. 1 Micrograph of the selected 40NiCrMo16 hardened steel.

Table 1 Chemical composition of the selected 40NiCrMo16 hardened steel.

\begin{tabular}{llllll}
\hline Elements & Carbon $(\mathrm{C})$ & Chromium $(\mathrm{Cr})$ & Molybdenum $(\mathrm{Mo})$ & Nickel $(\mathrm{Ni})$ & $\mathrm{Fer}(\mathrm{Fe})$ \\
\hline Composition $($ mass \%) & 0.45 & 1.30 & 0.30 & 4.10 & balance \\
\hline
\end{tabular}


Table 2 Properties of the micro tools (* manufacturer's data).

\begin{tabular}{lllll}
\hline Mills & Type 1 & Type 2 & Type 3 & Type 4 \\
\hline Coating* & AlCrN & AlCrN & TiAlN based & TiSiN \\
\hline Helix angle (degrees, $+/-1)^{*}$ & 5 à 15 & 30 & 30 & 20 \\
Orthogonal rake angle (degrees, $+/-1)^{*}$ & 7 & 0 & 10 & 10 \\
Length of the active zone $(\mathrm{mm}) *$ & 0.6 & 0.75 & 0.4 & 0.35 \\
Diameter clearance $(\mathrm{mm},+/-0.01)^{*}$ & 0.5 & 0.35 & 0.42 & 0.43 \\
Tool breakage force $(\mathrm{N},+/-0.5)$ & 27.7 & 19.6 & 24.2 & 25 \\
\hline
\end{tabular}

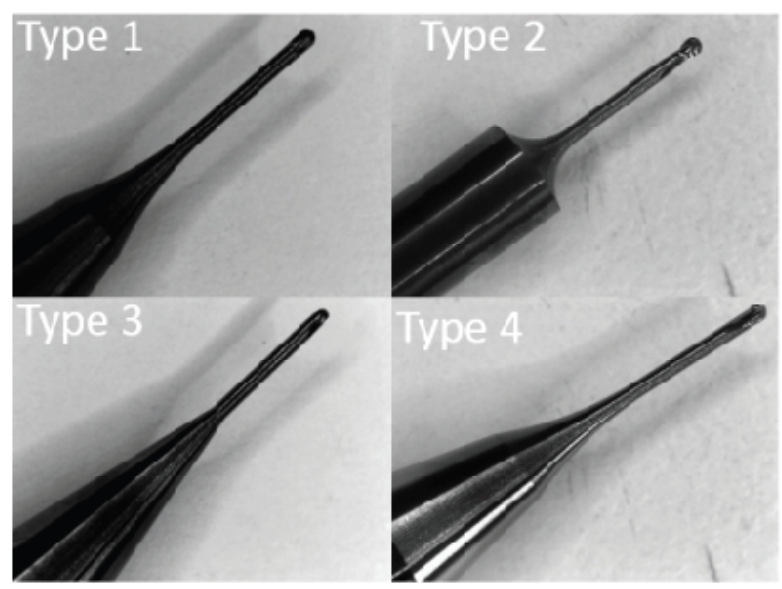

Fig. 2 Global geometry of the tested micro ball-end mills.

Mikron 400U-LP machining center. The used HSK 40 attachment allows a run-out lesser than $3 \mu \mathrm{m}$. Cutting forces measures were realized with a high sensitivity 3 components Kistler dynamometer (type Minidyn 9256C1). Measured cutting forces being relatively stable, it is possible to take as an evaluation criterion an average cutting force level. In this view, we define a line passing through the crests of resultant force $R_{x y z}$ signal (Fig. 3). This choice allows us to avoid taking into account the dynamic phenomena associated to the input and output of tool in work piece material.

Surface roughness at the bottom of slots has been measured with an Alicona Infinite Focus confocal microscope. In order to obtain a good representation of the milling surface and to not avoid some defects when positioning the reference line, the $S q$, defined by the standard 25178, was chosen as main roughness criterion. The surface of acquisition patch was $1,000 \mu \mathrm{m} \times 600 \mu \mathrm{m}$. On this surface, three measurement patches with an area of $500 \mu \mathrm{m} \times 100 \mu \mathrm{m}$ are scanned in the center of slots in order to obtain a better average estimation of roughness over the entire machined surface. The profile was defined at the center of slots, in the machining direction. A SEM was used to analyze tools wear.

\subsection{Experimental Plan}

For this study, a simple machining operation has been selected, in this case a slotting operation. This allows studying in a simple way all the cutting edge engagement configurations and simplifies machining parameters (e.g. cutting mode, radial depth of cut). The programmed normal depth of cut is fixed to $d_{n}=50 \mu \mathrm{m}$. All micro-milling tests were performed with the same HSK attachment and collet, to ensure a run out lesser than $3 \mu \mathrm{m}$. The sample dimensions are $80 \mathrm{~mm} \times 30 \mathrm{~mm}$ $\times 5 \mathrm{~mm}$ (Fig. 4) which corresponds approximately to the size of the upper plate of the dynamometer. They are fixed with 6 screws M3 torqued to $1.5 \mathrm{~N} \cdot \mathrm{m}$. To minimize the parallelism defect of samples, a grinding operation was carried out on their upper and lower surfaces before mounting for testing. The value of tool length is obtained by a laser system (Blum MT200). A correction is systematically performed on this value, with a tool/work piece contact approach micron by micron with force detection on dynamometer. All tests were carried out with micro-lubrication (Lenox 68014L).

According to the tools manufacturer recommendations, two machining strategies are relevant. The first one recommends a small feed per tooth of $2 \mu \mathrm{m} /$ tooth or lower, and the second a medium/high feed per tooth about $10 \mu \mathrm{m} /$ tooth.

The injection molds exhibit generally complex shapes which require four or even five axis to control tool/surface tilt. Two tool/surface tilt angles can be 


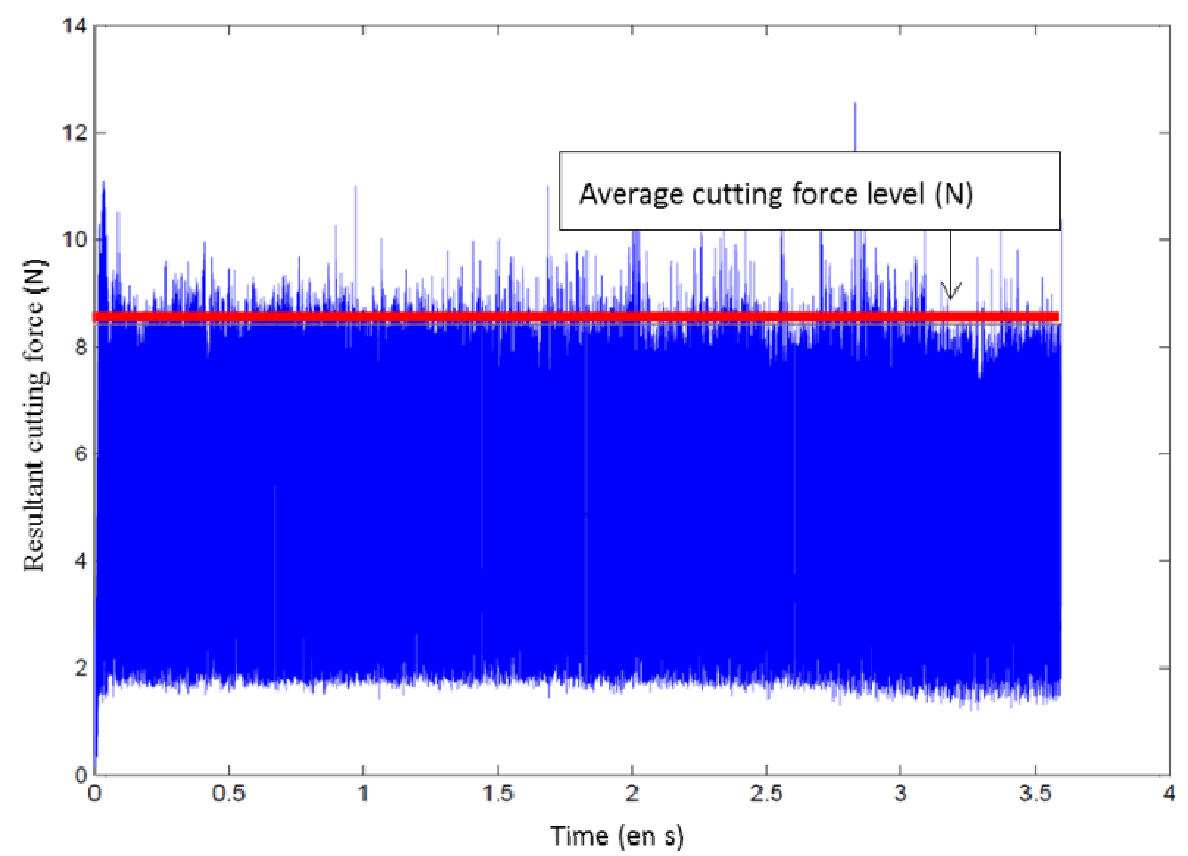

Fig. 3 Resultant cutting force defined from cutting forces measures obtained during a slotting test $\left(\mathrm{N}=40,000 \mathrm{rpm}, \mathrm{d}_{\mathrm{n}}=\right.$ $50 \mu \mathrm{m}, \delta_{\mathrm{f}}=0^{\circ}, \delta_{\mathrm{n}}=0^{\circ}, f_{\mathrm{t}}=6 \mu \mathrm{m} /$ tooth).

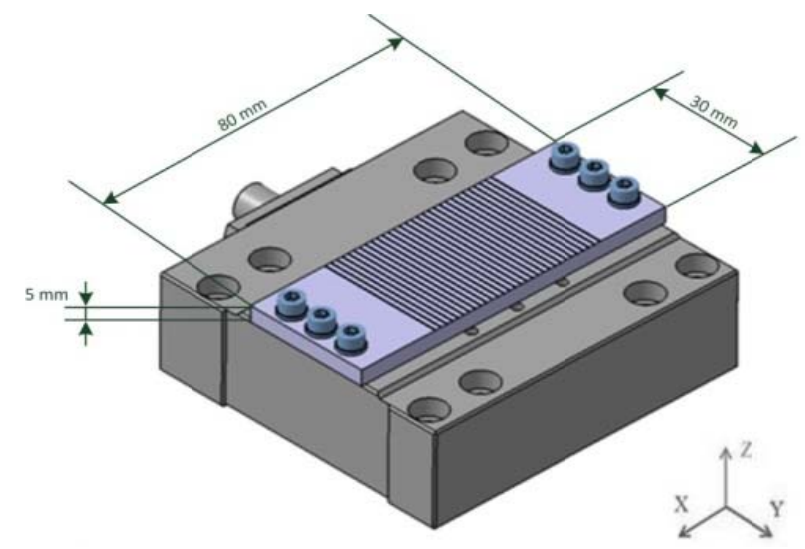

Fig. 4 Geometry and positioning of samples on the dynamometer.

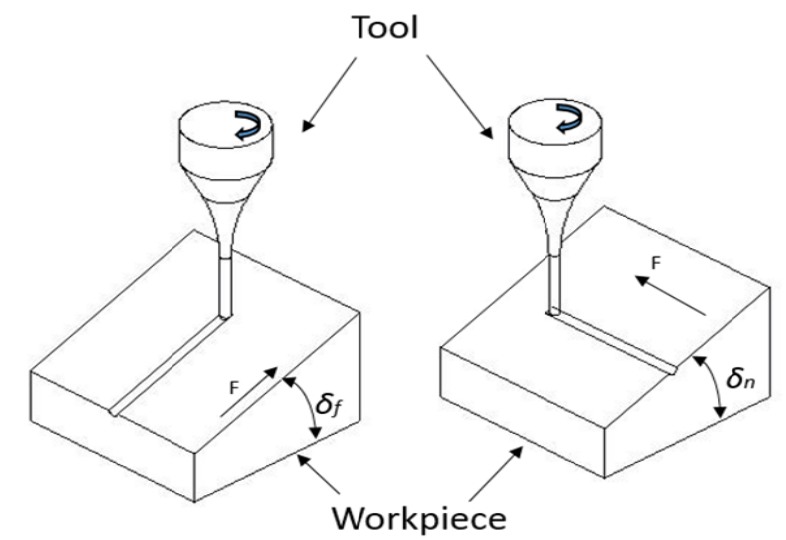

Fig. 5 Two reference configurations of tool/surface inclination. used to optimize the cutting process when using a hemispherical tool [12]. The main point is to choose the appropriate direction and angle value when tilting the micro-mill. To find the best inclination configuration, two directions of inclination were considered. The first $\delta_{f}$ is measured from feed direction, and the second $\delta_{n}$ from a direction normal to the feed (Fig. 5). The choice of reference values was inspired by previous works on macro ball-end milling [13].

Table 3 presents the experimental plan defined for this study. The selected values of spindle speed $(N)$ and feed per tooth $\left(f_{t}\right)$ result from manufacturers recommendations and our own experience in micro-milling for the same steel with micro-end mills [14]. The tool breakage force is an average value determined from tests without inclination.

Table 3 Characteristic of experimental plan.

\begin{tabular}{lll}
\hline Factors & Steps & Values \\
\hline$f_{t}(\mu \mathrm{m} /$ tooth $)$ & 20 & 2 à 40 \\
$N(\times 1,000 \mathrm{rpm})$ & 2 & 20,40 \\
$\delta_{f}\left({ }^{\circ}\right)$ & 3 & $0,-10,-20$ \\
$\delta_{n}\left({ }^{\circ}\right)$ & 2 & $(-20), 0,20$ \\
\hline
\end{tabular}


The execution of the experimental plan was performed by machining positions, that is to say a test corresponds to a fixed value of $\delta_{f}, \delta_{n}$ and $\mathrm{N}$, with a progressive increase of the feed rate $\left(f_{t}\right.$, step: 2 $\mu \mathrm{m} /$ tooth). This leads to use the same tool to scan all the feed rates range. Therefore, a total of 48 experiments is necessary to achieve the experimental plan. The mill is used to make grooves with $40 \mathrm{~mm}$ length and it has to reach 1,200 $\mathrm{mm}$ machined. Each related result is then slightly influenced by wear, but it is assumed negligible compared to the influence of the studied parameters. The main evaluation criteria were surface roughness, cutting forces and tool wear.

\section{Experimental Results}

\subsection{Effect of Feed Rate}

Fig. 6 shows the influence of feed rate on the evolution of the resultant cutting force. For these tests, a configuration without tool/surface tilt (3-axis) with a spindle speed of 40,000 rpm showed that cutting forces increase quasi-linearly with feed rate. This is true for the 4 types of micro-mills. However, it is important to note that this evolution is influenced by tool wear. The obtained curves indicate that types 2, 3 and 4 have a similar behavior. Nerveless, type 1 can be discriminated from the others by a sharp increase of cutting forces. This is probably due to a less accurate edge preparation on the ball-end which generates a plowing force much more important than for the other tools. For type 4, a sudden breakage happens at 20 $\mu \mathrm{m} /$ tooth, certainly related to coating delamination in relation to observations made in microscopy.

The influence of feed rate on surface roughness is presented in Fig. 7. For very low feed rates, all types are substantially equivalent. However, for higher feed rates, type 2 seems to maintain a better surface roughness quality.

Fig. 8 illustrates the aspect of slots as a function of feed per tooth $f_{t}$. The slots are machined with mill type 2 . For a very low feed per tooth $(2 \mu \mathrm{m} /$ tooth $)$, the edge radius of micro-tool, equal to some microns (approximately 4 microns), becomes important comparing to the undeformed chip thickness and modifies the cutting process (Fig. 8a). The material is then smoothed and cold worked in the center of the groove. With the increase of feed rate, the plowing effect becomes larger in the center of slots (Fig. 8b). It is then possible to identify three different areas in grooves topography: A first area corresponding to tool engagement (to the left of each groove on Fig. 8) in

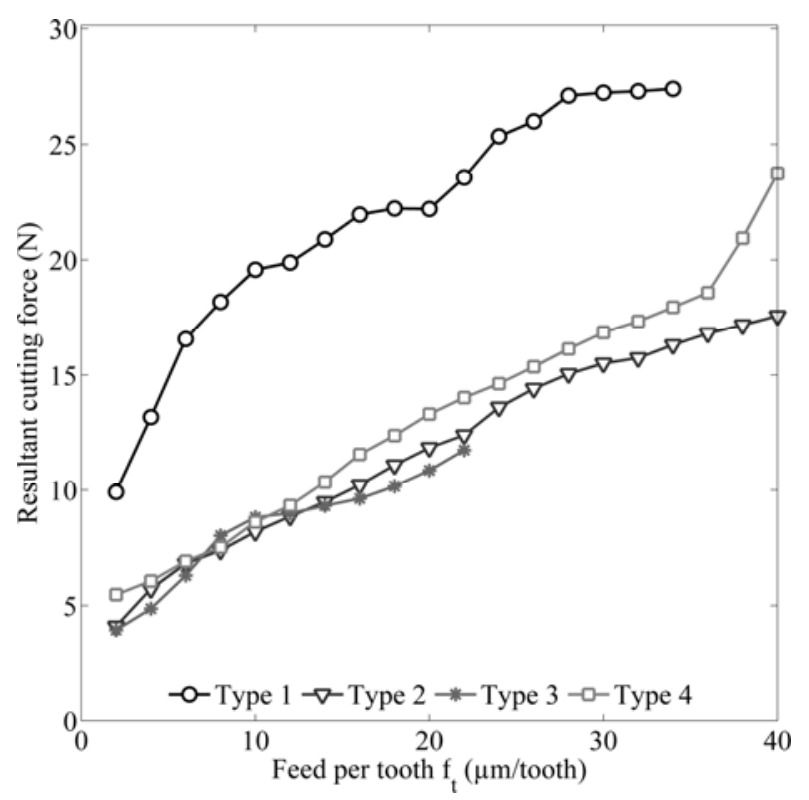

Fig. 6 Resultant cutting force as a function of feed rate $\left(N=40,000 \mathrm{rpm}, d_{n}=50 \mu \mathrm{m}, \delta_{f}=0^{\circ}, \delta_{n}=0^{\circ}\right)$. 


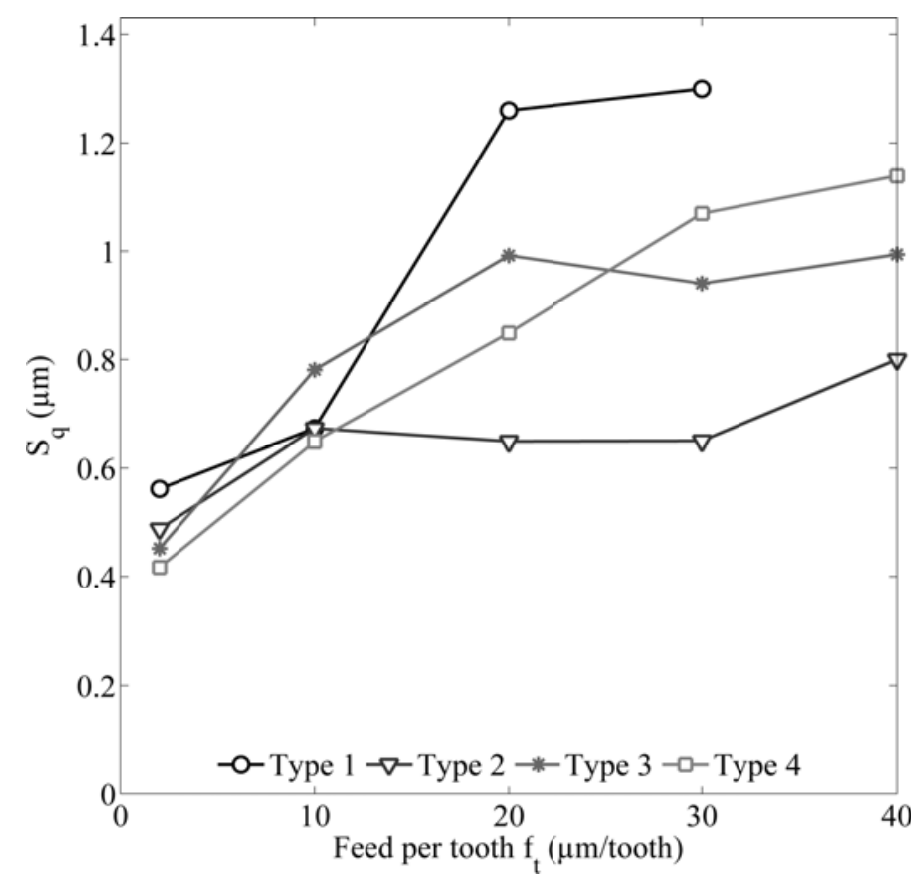

Fig. 7 Root mean square height as a function of feed rate $\left(\mathrm{N}=40,000 \mathrm{rpm}, d_{\mathrm{n}}=50 \mu \mathrm{m}, \delta_{\mathrm{f}}=0^{\circ}, \delta_{\mathrm{n}}=0^{\circ}\right)$.

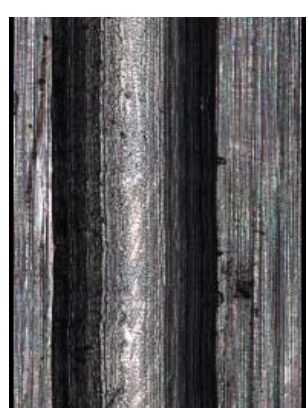

$2 \mu \mathrm{m} /$ tooth

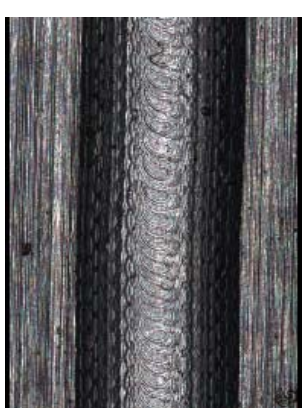

(b)

$20 \mu \mathrm{m} /$ tooth

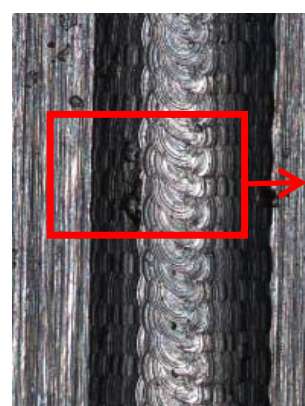

(c)

$40 \mu \mathrm{m} /$ tooth

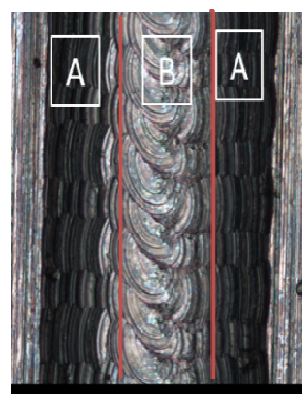

A: slicing and smoothing intermittently zone $\mathrm{B}$ : plowing zone

Fig. 8 Evolution of slots aspect depending on feed rate $\left(N=40,000 \mathrm{rpm}, d_{n}=50 \mu \mathrm{m}, \delta=0^{\circ}, \delta_{n}=0^{\circ}\right.$, type 2).

which the machined material seems sliced and smoothed intermittently; A second area where plowing is prevailing. Finally, a third area similar to the first. For the case of flat machining (no tool/surface inclination), a reduction of the feed rate tends to stabilize cutting. It reduces the dynamic instability as well as the importance of the plowing zone.

\subsection{Influence of Tool/Surface Inclination}

To increase tool life and keep a good quality of the machined surface, it is conventionally recommended to avoid machining with a null local cutting speed (when tool is normal to the machined surface) [13]. Using a tool/surface tilt allows to limit the problems of cutting refusal and material plowing that degrade machined surface quality and tool life.

Fig. 9 shows the influence of tool/surface inclination in feed direction for type 2, with a spindle speed of $40,000 \mathrm{rpm}$. As announced by various studies in macro-machining [13] and micro-machining [12, 15, 16], a tool/surface inclination towards the front in feed direction $\left(\delta_{f}>0\right)$ generates lower cutting forces than in other configurations. In a configuration without inclination $\left(\delta_{f}=\delta_{n}=0^{\circ}\right)$, the tool generates more cutting forces, and this leads to a potential quick breakage.

With inclination, the tool end is out of material, so cutting is more stable. The cutting forces are reduced 


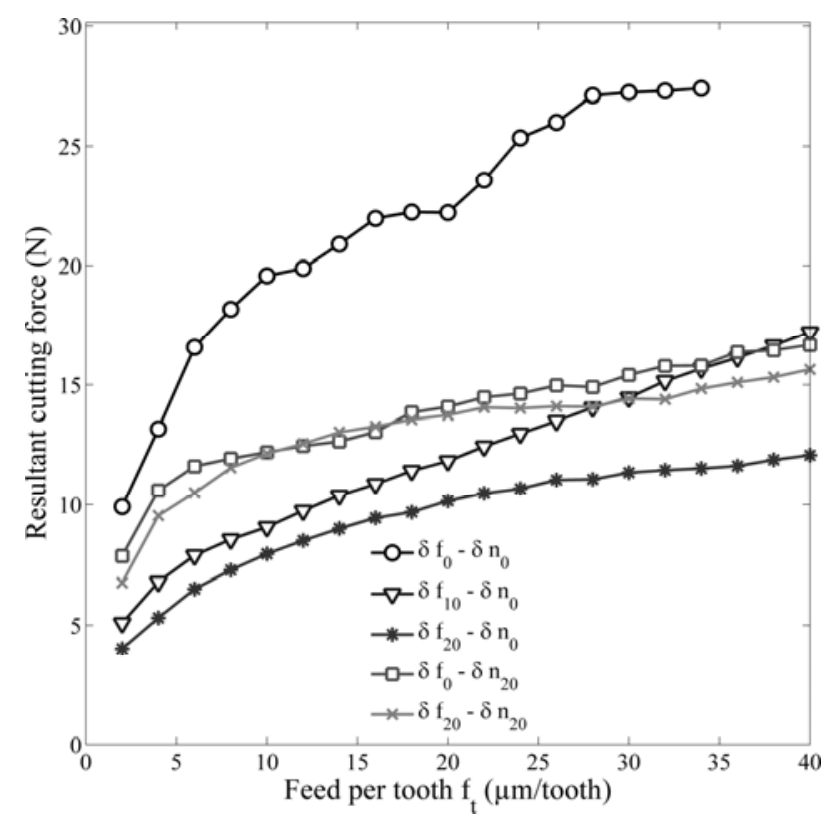

Fig. 9 Evolution of feed per tooth on resultant cutting force for different tool/surface inclinations in feed direction (mill type $\left.1, \mathrm{~N}=40,000 \mathrm{rpm}, \mathrm{d}_{\mathrm{n}}=\mathbf{5 0} \mu \mathrm{m}\right)$.

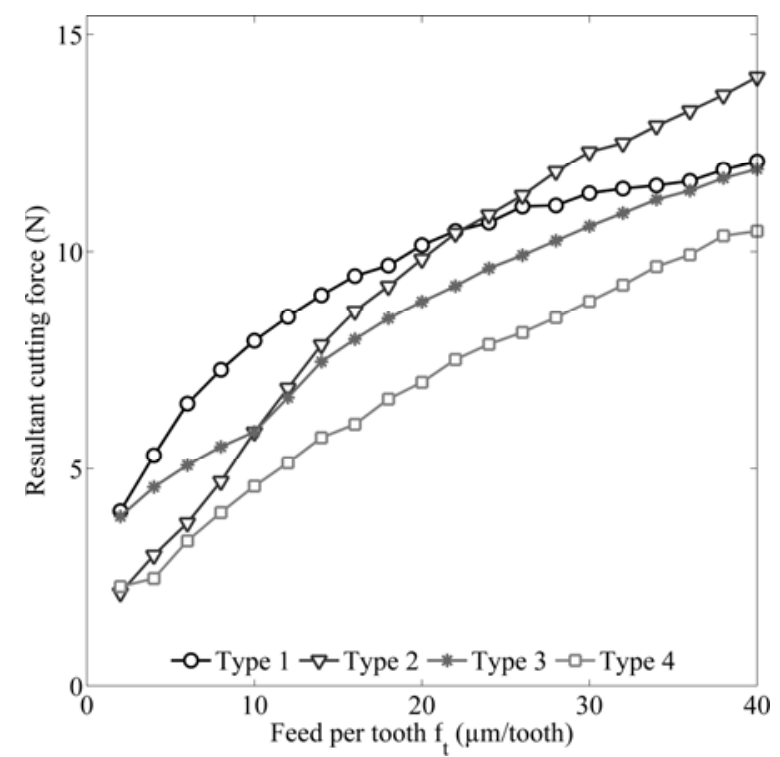

Fig. 10 Influence of feed per tooth on resultant cutting force for different mill type $\left(N=40,000 \mathrm{rpm}, \mathrm{d}_{\mathrm{n}}=50 \mu \mathrm{m}, \delta_{\mathrm{f}}=20^{\circ}\right.$, $\left.\boldsymbol{\delta}_{\mathbf{n}}=\mathbf{0}^{\circ}\right)$.

and the surface roughness is improved (Fig. 10). By comparing the different tools efficiency, it has been found that using an inclination decreases the discrepancy between tested micro-mills. This tends to demonstrate the importance of cutting edge preparation at tool end. This preparation is quite different from one type to another and greatly influences the results in the case of flat machining configuration. SEM observations show that the increased force generated by tool type 2 is due to a discontinuity in cutting edge preparation and results in a lack of local resistance and in accelerated wear (for confidentiality reasons it is not possible to show these pictures). The trends observed for the different tools are similar.

\subsection{Dynamic Behavior}

The micro-mills are often characterized by a low rigidity and this has several consequences during 
micromachining operations. Figs. 11a and $11 \mathrm{~b}$ show the aspect of the beginning of slot made by tool 3 for a feed per tooth of 2 and $40 \mu \mathrm{m} /$ tooth respectively. This comparison highlights a lack of rigidity. The mills tend to deflect in transverse direction at the beginning of machining when high feeds are used. Consequently, the settings of depth of cut and trajectory are not respected.

Similarly, the lack of tool rigidity generates a phenomenon of over- or under-depth of cut depending on cutting modes. Fig. 12 represents measured values of the effective depth of cut depending on feed rate for different machining configurations. The error on normal depth of cut can reach up to $50 \%$. A solution can be provided to compensate this error, as demonstrated by Dow T. A. et al. [6], by correcting the depth of cut using a calculation performed with a tool deflection model. When the contouring configuration gives priority to up-cutting mode, then the orientation of the cutting forces leads to an increase in the depth of cut. For contouring configurations with priority to down-cutting mode, the tool is removed from the material thus is taking less material during cutting.

\subsection{Tools Wear}

Specific wear tests were carried out in micro-milling to estimate tools life and identify wear mechanisms. The slots had a length of $30 \mathrm{~mm}$, a depth of cut of 0.5 $\mathrm{mm}$ and the experimental protocol was the same as previous tests. In agreement with manufacturers recommendations, a very low feed rate value was used. To consider a zone where all mills have a quite similar

\section{a) $f_{t}: 2 \mu \mathrm{m} /$ tooth $\quad$ b) $f_{t}: 40 \mu \mathrm{m} /$ tooth}

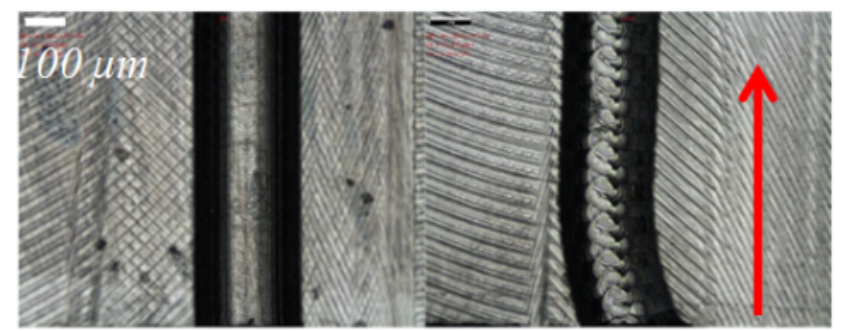

\section{Machining direction}

Fig. 11 Observation of aspect of slots at very low feed rate and high feed rate (tool type 3).

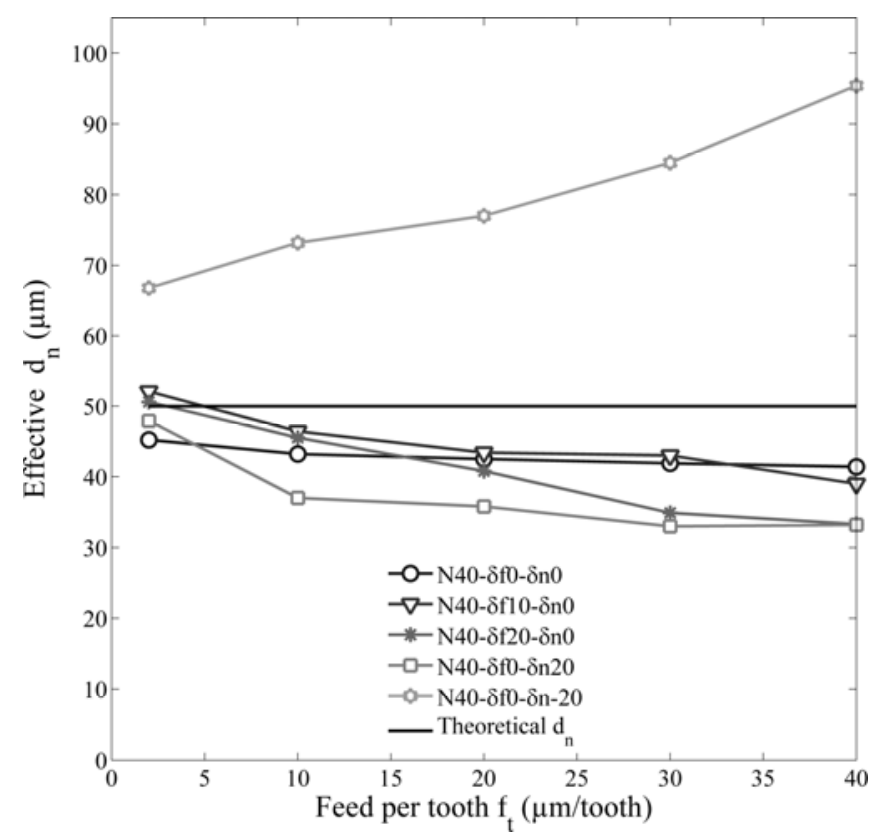

Fig. 12 Evolution of the effective normal depth of cut versus feed rate for various configurations (tool type 2). 
behavior, a spindle speed of 40,000 rpm was chosen. The results highlight a relationship between tools wear, local tools geometry and feed rate.

At the scale of micro-milling process, a strategy using high feed rates often involves a deterioration of surface roughness [17] and a decrease of tool life. To identify the influence of feed rate on tool life, two values were tested out: 2 and $6 \mu \mathrm{m} /$ tooth. The criteria retained for tool life estimations are the resultant cutting force and burrs occurrence.

As demonstrated by the previous test, type 1 is not really appropriate to machine hardened tool steels. It generates higher forces than the other mills and a poor surface quality (Figs. 13 and 14). Whatever the feed rate value is, the same tendency is observed. As in conventional milling, the tool life goes down when feed rate increases and the cutting forces level is more stable. Mills types 1 and 3 are made of the same tungsten

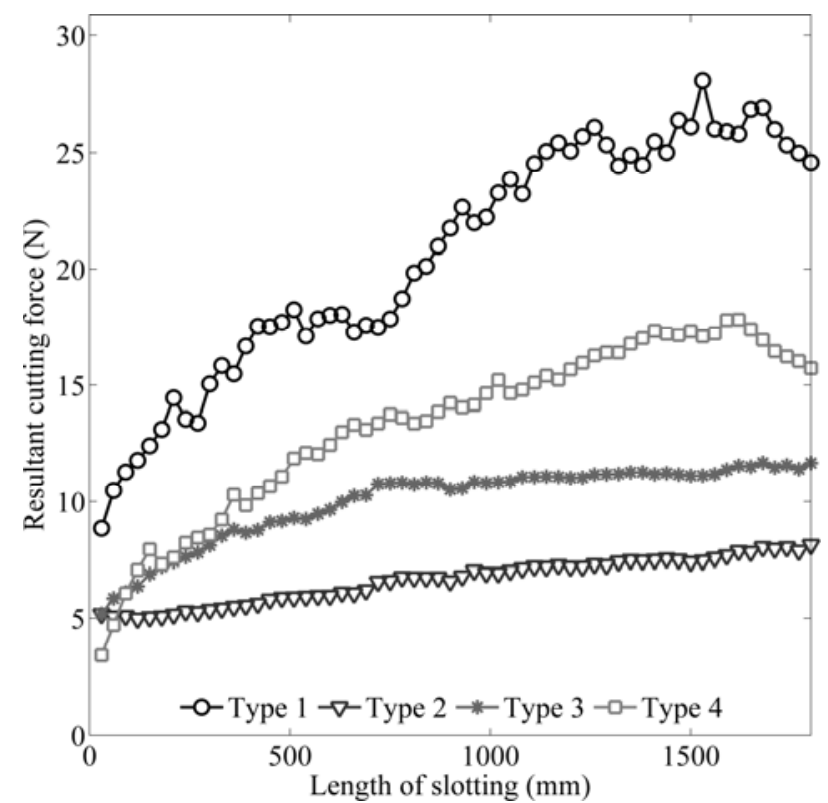

Fig. 13 Evolution of the resultant cutting forces versus machined length for feed rate of $2 \mu \mathrm{m} / \mathrm{tooth}\left(\mathrm{N}=40,000 \mathrm{rpm}, \mathrm{d}_{\mathrm{n}}=\right.$ $\left.50 \mu \mathrm{m}, \delta_{\mathrm{f}}=\mathbf{0}^{\circ}, \delta_{\mathrm{n}}=\mathbf{0}^{\circ}\right)$.

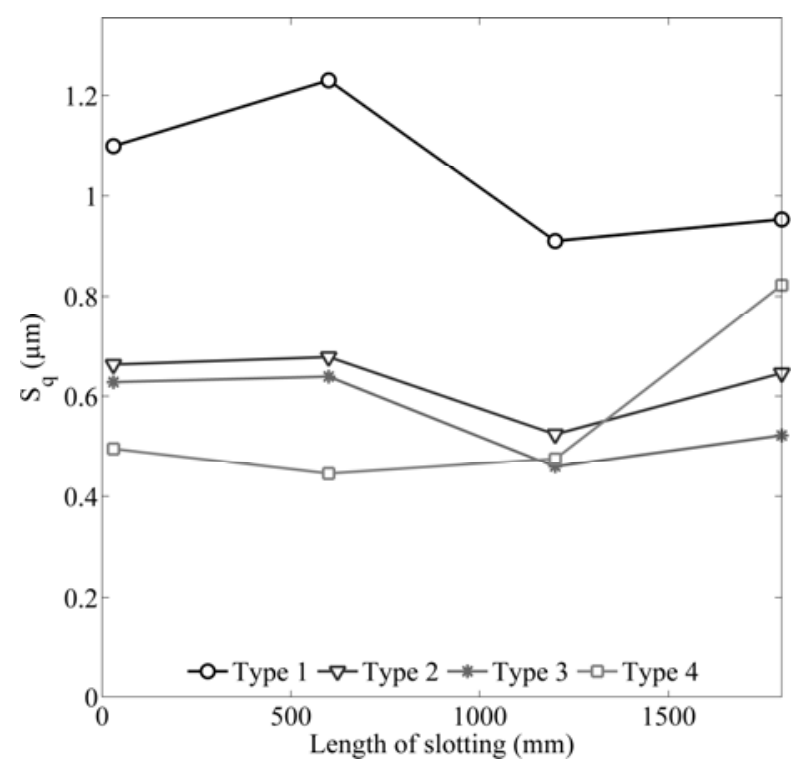

Fig. 14 Evolution of root mean square height versus machined length for feed rate of $2 \mu \mathrm{m} /$ tooth $\left(\mathrm{N}=40,000 \mathrm{rpm}, d_{\mathrm{n}}=50 \mu \mathrm{m}\right.$, $\boldsymbol{\delta}_{\mathrm{f}}=\mathbf{0}^{\circ}, \boldsymbol{\delta}_{\mathrm{n}}=\mathbf{0}^{\circ}$ ). 




Fig. 15 Aspect of slots for types 2 and 3 micro-mills for feed rate of 2 and $6 \mu \mathrm{m} /$ tooth.

Type 1

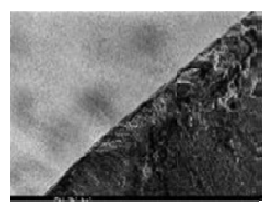

Fig. 16 Flank wear of micro-mills types 1, 2 and 3 after $1,800 \mathrm{~mm}$ of slotting $\left(\mathrm{N}=40,000 \mathrm{rpm}, \mathrm{d}_{\mathrm{n}}=50 \mu \mathrm{m}, \delta_{\mathrm{f}}=0^{\circ}\right.$, $\left.\boldsymbol{\delta}_{\mathrm{n}}=\mathbf{0}^{\circ}\right)$.

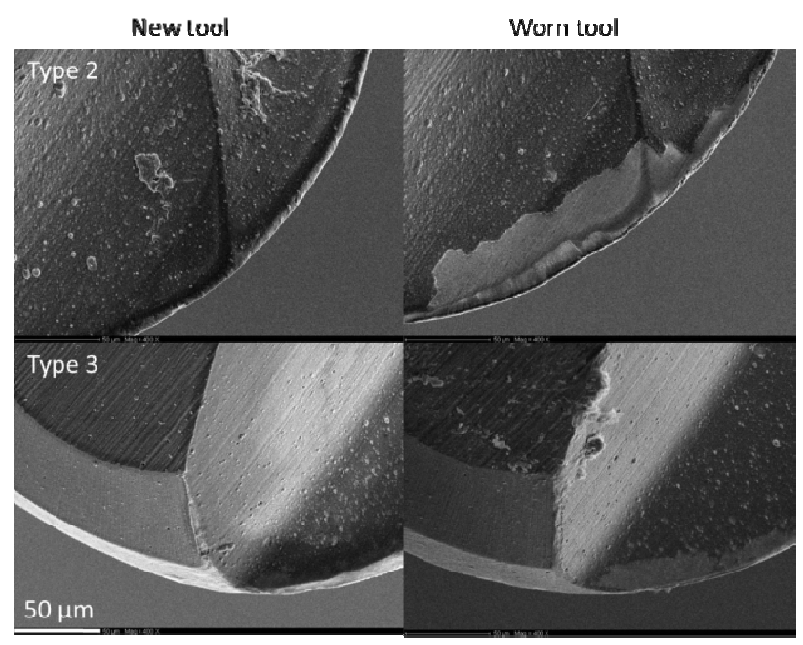

Fig. 17 Face wear of micro-mills types 2 and 3 after 1,800 mm of slotting $\left(N=40,000 \mathrm{rpm}, d_{n}=50 \mu \mathrm{m}, \delta_{\mathrm{f}}=20^{\circ}, \delta_{\mathrm{n}}=0^{\circ}\right.$, $f_{t}=2 \mu \mathrm{m} /$ tooth).

carbide and coating. The main difference is a specific preparation at the tool end for type 2 . The rake angle is equal to 0 degree. This provides manifestly a greater resistance in this zone than for the other mill types.

For a low feed rate ( $2 \mu \mathrm{m} /$ tooth) burrs occur with types 1, 3 and 4. As a consequence, a burrs removal operation will be necessary for an injection molding application. When feed rate increases ( $6 \mu \mathrm{m} /$ tooth $)$, no burr is present. Considering this criterion, the more interesting micro-mill is type 2 (Fig. 15). In fact, this tool has higher life expectancy because it shows a stable behavior for low or very low feed rates. This behavior allows testing medium or high feed rate to reduce exit-burrs without a quickly breakage of the mill. To well understand the different behaviors, it is necessary to investigate further the evolution of tools wear and the associated mechanisms, especially at the carbide/coating interface.

Fig. 16 shows the flank wear on mills types 1,2 and 3 after slotting along $1,800 \mathrm{~mm}$ as defined previously. It is possible to observe that wear mechanisms slightly differ from one tool to another but always conduct to recoil and degradation of the cutting edge.

The wear on the rake face for mill types 2 and 3 is presented on Fig. 17. The main wear mechanism is clearly abrasion. According to previous results on machined parts quality and this observation, it seems that for these applications a rake angle equal to $0^{\circ}$ reduces wear by abrasion without damaging surface roughness. For this tool the specific edge preparation at the tool end seems to be less interesting for tilted machining due to a discontinuity in the cutting edge that leads to accelerate wear in this zone. About coatings, AlCrN reduces flank wear compared to TiAlN, and this is consistent with conclusions of Ucun I. et al. [18]. The comparison of the four tool types showed a problem of adhesion between the carbide and the coating for one of them (type 2). This is put in evidence by the presence of chipping on the cutting face (Fig. 17).

\section{Conclusions and Prospects}

This paper presents an experimental investigation in micro ball-end milling of a hardened tool steel dealing with the influence of cutting conditions and tool geometry on cutting efficiency. The main conclusions are:

The best way to reduce exit-burrs is to increase the feed rate. In this way, it is necessary to use stiffer micro 
mills. Unlike conventional milling, the increase of feed rate has no significant impact on surface roughness.

The local geometry of micro-mills has more influence on wear resistance than on machined parts quality. Unlike conventional milling, a rake angle equal to zero at the tool tip allows reducing the tool wear without increasing the cutting forces and burrs occurrence.

The lack of rigidity of micro-mills leads to the development of dynamic phenomena and an important deflection of the tool responsible of potentially high errors in machined surface positioning, and even quick tool breakage.

The final purpose of this work is to optimize the micro ball-end mills and their requirements for dies and molds industry. From this point of view, new milling tests with suitable experimental devices (high speed camera, precise 3D digitizing) will allow understanding further the dynamic behavior of cutting tools, optimizing the global geometry of considered micro-mills (core diameter, neck geometry) and developing new methods for the characterization of micro-milling process.

\section{Acknowledgment}

The authors thank sincerely Dr. Gérard Michel and Ing. Martial Personeni for their collaboration in preparing samples and setting up experiments. We would like to thank our industrial partner, Magafor, for providing tools and funds to support the project in association with the French National Association for Technological Research (ANRT).

These works were carried out in the context of the working group Manufacturing'21 gathering 18 french laboratories. Targeted issues are modeling and optimization of machining processes and innovation in the field of mechanical manufacturing.

\section{References}

[1] Masuzawa, T. and Tonshoff, H. 1997. "Three-Dimensional Micromachining by Machine Tools." Scientific Technical Committe Paper 46 (2): 621-8.
[2] Freidrich, C. and Coane, P. 1997. "Micro Milling Development and Applications for Micro Fabrication." Microelectronic Engineering 35: 367-72.

[3] Ng, C., Melkote, S., Rahman, M. and Kumar, A. 2006. "Experimental Study of Micro- and Nano-Scale Cutting of Aluminum 7075-T6." International Journal of Machine Tools and Manufacture 46 (9): 926-36.

[4] Aramchareon, A. and Matinvenga, P. 2009. "Size Effect and Tool Geometry in Micromilling of Tool Steel." Precision Engineering 33 (4): 402-7.

[5] Bissacco, G., Hansen, H. N. and De Chiffre, L. 2006. "Size Effects on Surface Generation in Micro Milling of Hardened Tool Steel." Annals of the CIR 55 (1): 593-6.

[6] Dow, T. A., Miller, E. L. and Garrard, K. 2004. "Tool Force and Deflection Compensation for Small Milling Tools." Precision Engineering 28: 31-45.

[7] Dépincé, P. and Hascoët, J. Y. 2006. “Active Integration of Tool Deflection Effects in End Milling. Part I: Prediction of Milled Surfaces." International Journal of Machine Tools \& Manufacture 46: 937-44.

[8] Altintas, Y. 2000. "Manufacturing Automation: Metal Cutting Mechanics, Machine Tool Vibrations and CNC Design." Cambridge University.

[9] Rahnama, R., Sajjadi, M. and Park, S. S. 2009. "Chatter Suppression in Micro End Milling with Process Damping." Journal of Materials Processing Technology 209: 5766-76.

[10] Li, P., Oosterling, J. A. J., Hoogstrate, A. M., Langen, H. H. and Munnig Schmidt, R. H. 2011. "Design of Micro Square Endmills for Hard Milling Applications.” Journal of Advanced Manufacturing Technology 57: 859-70.

[11] Bissacco, G., Hansen, H. and Chiffre, L. D. 2005. "Micromilling of Hardened Tool Steel for Mould Making Applications." Journal of Materials Processing Technology 167: 201-7.

[12] Toh, C. K. 2004. "A Study of the Effects of Cutter Path Strategies and Orientations in Milling." Journal of Materials Processing Technology 152 (3): 346-56.

[13] Fontaine, M., Devillez, A., Moufki, A. and Dudzinski, D. 2007. "Modelling of Cutting Forces in Ball-End Milling with Tool - Surface Inclination Part II. Influence of Cutting Conditions, Run-Out, Ploughing and Inclination Angle." Journal of Materials Processing Technology 189: 85-96.

[14] Gilbin, A. and Fontaine, M. 2013. "Capability of Tungsten Carbide Micro-Mills to Machine Hardened Tool Steel." 1 (14): 23-8.

[15] Fard, J. B. M. and Bordatchev, E. 2013. "Experimental Study of the Effect of Tool Orientation in Five-Axis Micro-Milling of Brass Using Ball-End Mills." International Journal of Advanced Manufacturing Technology 67: 1079-89. 
[16] Arif, M., Rahman, M. and San, W. Y. 2012. "An Experimental Investigation into Micro Ball End-Milling of Silicon." Journal of Manufacturing Processes 14: 51-61.

[17] Raju, K., Kumar, G. and Rao, V. 2011. "Optimization of Cutting Conditions for Surface Roughness in CNC End
Milling." International Journal of Precision Engineering and Manufacturing 12 (3): 383-91.

[18] Ucun, I., Kubilay, A. and Fevzi, B. 2013. "An Experimental Investigation of the Effect of Coating Material on Tool Wear in Micro Milling of Inconel 718 Superalloy." Wear 300 (1-2): 8-19. 